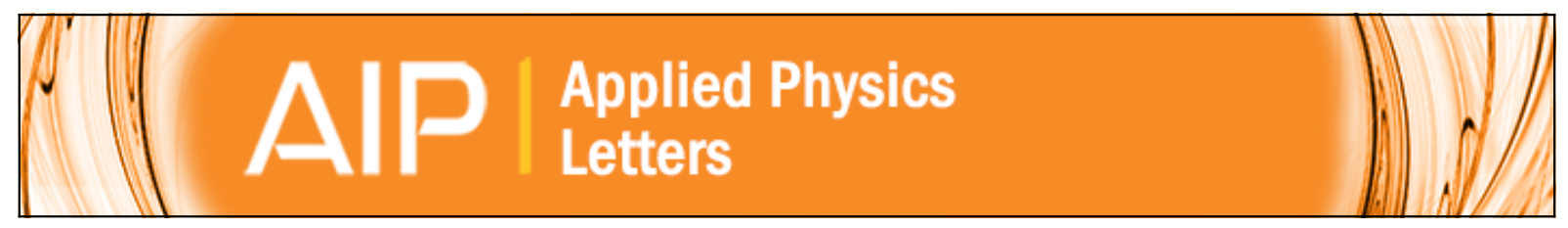

\title{
Atomic scale nitrogen depth profile control during plasma enhanced atomic layer deposition of high $\mathbf{k}$ dielectrics
}

W. J. Maeng and H. Kim

Citation: Applied Physics Letters 91, 092901 (2007); doi: 10.1063/1.2776350

View online: http://dx.doi.org/10.1063/1.2776350

View Table of Contents: http://scitation.aip.org/content/aip/journal/apl/91/9?ver=pdfcov

Published by the AIP Publishing

\section{Articles you may be interested in}

Improved thermal stability and electrical properties of atomic layer deposited HfO2/AIN high-k gate dielectric stacks on GaAs

J. Vac. Sci. Technol. A 33, 01A136 (2015); 10.1116/1.4903367

Characterization of HfO2/La2O3 layered stacking deposited on Si substrate

J. Vac. Sci. Technol. B 31, 01A113 (2013); 10.1116/1.4770497

Comparative band alignment of plasma-enhanced atomic layer deposited high-k dielectrics on gallium nitride J. Appl. Phys. 112, 053710 (2012); 10.1063/1.4749268

Low temperature growth of high-k Hf-La oxides by remote-plasma atomic layer deposition: Morphology, stoichiometry, and dielectric properties

J. Vac. Sci. Technol. A 30, 01A147 (2012); 10.1116/1.3665419

Thermodynamic properties and interfacial layer characteristics of $\mathrm{Hf} \mathrm{O} 2$ thin films deposited by plasmaenhanced atomic layer deposition

Appl. Phys. Lett. 90, 222101 (2007); 10.1063/1.2743749

You don't

still use this

cell phone

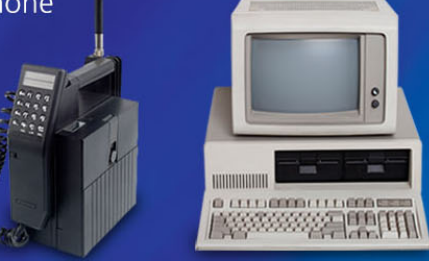

Why are you

still using an

AFM designed in the $80^{\prime}$ 's?
It is time to upgrade your AFM Minimum \$20,000 trade-in discount for purchases before August 31st

Asylum Research is today's technology leader in AFM

dropmyoldAFM@oxinst.com

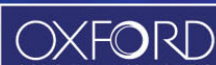

OXFORD INSTRUMENTS The Business of Science 


\title{
Atomic scale nitrogen depth profile control during plasma enhanced atomic layer deposition of high $\boldsymbol{k}$ dielectrics
}

\author{
W. J. Maeng and H. Kim ${ }^{\mathrm{a})}$ \\ Department of Materials Science and Engineering, Pohang University of Science and Technology \\ (POSTECH), San 31, Hyoja-Dong, Nam-Gu, Pohang 790-784, Korea
}

(Received 1 June 2007; accepted 5 August 2007; published online 27 August 2007)

\begin{abstract}
Nitrogen incorporation produces several benefits in the performance of high $k$ gate oxides. However, since too much nitrogen incorporation at the interface of gate dielectric can result in device degradation, the atomic scale control of nitrogen depth profile is desirable. In this study, the authors have improved electrical properties and interface properties by depth profile control of in situ nitrogen incorporation during plasma enhanced atomic layer deposition. The best electrical properties in terms of hysteresis, equivalent oxide thickness, and interface states were obtained when the nitrogen is incorporated in the middle of the thin film, which has not been achievable by other techniques. (C) 2007 American Institute of Physics. [DOI: 10.1063/1.2776350]
\end{abstract}

The incorporation of nitrogen atoms reduces the leakage currents and improves the reliability of the metal-oxidesemiconductor field effect transistors by prohibiting boron penetration, passivating oxygen vacancy states, and enhancing structural stability. ${ }^{1}$ Generally, the nitrogen incorporation into gate oxide has been carried out by high temperature or plasma annealing of oxide films under nitrogen environment. However, since too much incorporation of nitrogen at the interface between channel region and gate oxide induces large flatband voltage shift resulting in the mobility degradation, ${ }^{2}$ postdeposition nitridation process has been suggested. ${ }^{3,4}$ Comparative study between samples with nitride layer located at the bottom and top of oxide has shown better electrical properties for the top nitrided samples. ${ }^{3}$ However, with further scaling of devices into nanoscale regime, a more precise control of nitrogen depth profile would be desirable.

Due to its atomic scale thickness controllability, atomic layer deposition (ALD) is an ideal technique to produce thin films with atomically modulated compositional depth profiles. However, the incorporation of elements (additives or dopants) to thin films with predesigned depth profile during ALD has not been studied yet. Recently, we reported in situ nitrogen incorporation into $\mathrm{Ta}_{2} \mathrm{O}_{5}$ thin films during thermal and plasma enhanced ALD (PE-ALD) by employing $\mathrm{NH}_{4} \mathrm{OH}$ and $\mathrm{N} / \mathrm{O}$ mixture plasma as a source for reactants, which resulted in significantly improved electrical properties. ${ }^{5,6}$ In this letter, we show that atomic scale depth profile control of nitrogen is feasible by in situ nitrogen incorporation during ALD. The in situ nitridation during PEALD $\mathrm{HfO}_{2}$ was carried out by adding nitrogen to oxygen plasma. $\mathrm{HfO}_{x} \mathrm{~N}_{y}$ thin films with three different nitrogen depth profiles were prepared by incorporating nitrogen atoms into the bottom, middle, and top of the PE-ALD $\mathrm{HfO}_{2}$ thin films, and the effects of in situ nitridation and nitrogen depth profiling on the electrical properties were comparatively studied. It should be noted that although the nitrogen incorporation into the bottom and top of oxide has been performed by other nitridation techniques, ${ }^{3}$ the nitrogen incorporation into the middle of the oxide by one simple process step has not been

\footnotetext{
${ }^{a)}$ Electronic mail: hyungjun@postech.ac.kr
}

reported yet. The best electrical properties were obtained for this case.

A homemade remote plasma enhanced ALD system was used in this study. Tetrakis(dimethylamino)hafnium was used as a Hf precursor with oxygen and nitrogen as reactants. For in situ nitridation, the $\mathrm{N} / \mathrm{O}$ flow ratio was fixed at 2 . The impurity contents and chemical binding structures were analyzed by angle resolved $\mathrm{x}$-ray photoemission spectroscopy (AR-XPS) at $90^{\circ}$ and $30^{\circ}$ detection angles. For electrical measurements, metal-oxide-semiconductor (MOS) capacitors with dc sputtered $\mathrm{Pt}$ as electrodes were fabricated on $p$-type (boron, $5 \times 10^{14} / \mathrm{cm}^{3}$ ) $\mathrm{Si}(001)$ substrates. Postdeposition annealing (PDA) and forming gas annealing were carried out at $400{ }^{\circ} \mathrm{C}$ for $10 \mathrm{~min}$ in oxygen environment and for 30 min in $\mathrm{H}_{2} \quad 5 \%-\mathrm{N}_{2} \quad 95 \%$, respectively. Capacitancevoltage $(C-V)$ and current-voltage $(I-V)$ characteristics were determined by using Keithley 4200 semiconductor parameter analyzer with HP4284 LCR meter. The equivalent oxide thickness (EOT) values were extracted from $C$ - $V$ measurements using a resistance correction procedure carried out at two different measurement frequencies of 10 and $100 \mathrm{kHz},{ }^{7}$ and the interface state density $\left(D_{\mathrm{it}}\right)$ was obtained by conductance methods.

First, fully nitrided $\mathrm{HfO}_{x} \mathrm{~N}_{y}$ thin films were prepared in order to confirm the nitrogen incorporation through in situ nitridation during $\mathrm{PE}-\mathrm{ALD} \mathrm{HfO}_{2}$. The growth rate remained constant by adding the nitrogen to oxygen plasma (1.3 ̊/cycle) and $\mathrm{x}$-ray diffraction analysis has shown that all the films are amorphous at the low growth temperature used in this study $\left(250{ }^{\circ} \mathrm{C}\right)$. The nitrogen content in the film was determined to be $4.5 \%$ by XPS for fully nitrided $\mathrm{HfO}_{x} \mathrm{~N}_{y}$ thin film. The nitrogen incorporation during PE-ALD $\mathrm{HfO}_{2}$ has been recently reported by using $\mathrm{N}_{2} \mathrm{O}$ plasma as an oxidant. ${ }^{8}$ However, by the current process scheme using the mixture of nitrogen and oxygen gases, the nitrogen content is controlled more readily by changing the $\mathrm{N} / \mathrm{O}$ flow ratio. The effects of in situ nitridation on electrical properties were investigated by comparing the electrical properties of MOS capacitors with PE-ALD $\mathrm{HfO}_{2}$ and $\mathrm{HfO}_{x} \mathrm{~N}_{y}$ as dielectrics. The EOT value of $\mathrm{HfO}_{x} \mathrm{~N}_{y}(0.95 \mathrm{~nm})$ was smaller than that of $\mathrm{HfO}_{2}(1.15 \mathrm{~nm})$. This agrees with a previous report showing that $5 \% \mathrm{~N}$ incorporation in $\mathrm{HfO}_{2}$ films increases the dielectric constant by about $17 \%$. $^{9}$ However, the flatband volt- 

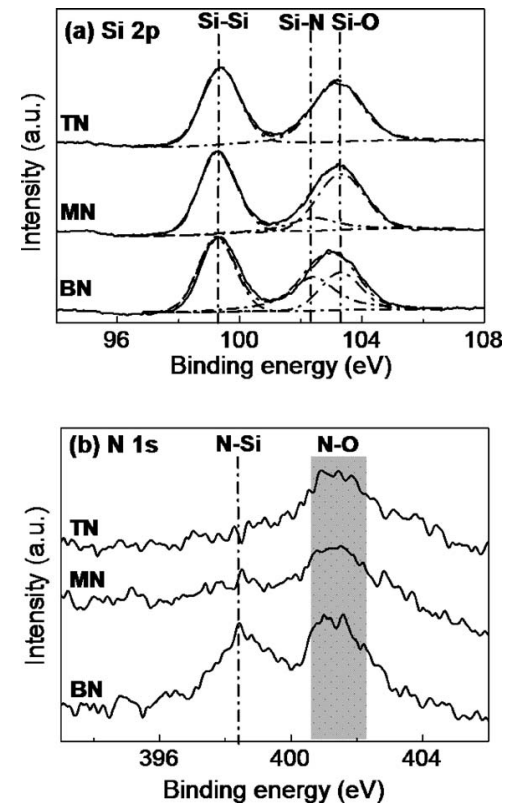

FIG. 1. (a) Si $2 p$ and (b) N $1 s$ XPS spectra of as-deposited BN (bottom nitridation), MN (middle nitridation), and TN (top nitridation).

age $\left(V_{\mathrm{FB}}\right)$ of $\mathrm{HfO}_{x} \mathrm{~N}_{y}$ is shifted to slightly negative direction with $\Delta V_{\mathrm{FB}}=-0.15 \mathrm{~V}$, and the hysteresis becomes larger (about $0.2 \mathrm{~V}$ ) compared to $\mathrm{HfO}_{2}$. Leakage current density of $\mathrm{HfO}_{x} \mathrm{~N}_{y}$ at $-1 \mathrm{MV} / \mathrm{cm}$ is $1 \times 10^{-7} \mathrm{~A} / \mathrm{cm}^{2}$, which is about ten times lower than that of $\mathrm{HfO}_{2}$ (data not shown). These results are consistent with previous reports indicating that too much nitrogen incorporation at the interface of high $k / \mathrm{Si}$ causes flatband voltage shift and large hysteresis, which would lead to the degradation of device performance. ${ }^{1}$ These results indicate that the depth profile control for nitrogen incorporation is highly desirable.

Thus, three different samples with atomically modulated nitrogen depth profiles were prepared. The positions of nitrided layers were controlled by changing the sequence of $\mathrm{O}$ plasma and N/O mixture plasma exposures to produce bottom nitridation $(\mathrm{BN})$, middle nitridation $(\mathrm{MN})$, and top nitridation (TN) samples. The total number of growth cycles was 30 for each sample, 20 cycles of $\mathrm{O}$ plasma and 10 cycles of N/O mixture plasma as a reactant, respectively. Figure 1(a) is the XPS spectra of these three samples in Si binding energy region, showing that each spectrum is composed of two peaks, a peak from $\mathrm{Si}-\mathrm{Si}$ bonding at $99.3 \mathrm{eV}$ and another peak at around $103.0 \mathrm{eV}$. While the positions of $\mathrm{Si}-\mathrm{Si}$ bonding peaks from the $\mathrm{Si}$ substrates are all the same for three spectra, the peak positions of higher binding energy are shifted to lower energy from sample TN to BN. By deconvolution, we found that while the high energy peak for $\mathrm{TN}$ is composed of entirely $\mathrm{Si}-\mathrm{O}$ peak at $103.3 \mathrm{eV}$, the peak for BN is actually composed of two peaks at 103.3 and $102.4 \mathrm{eV}$. The peak at $102.4 \mathrm{eV}$ is attributed to the $\mathrm{Si}-\mathrm{N}$ bonding. ${ }^{10}$ While the $\mathrm{Si}-\mathrm{N}$ peak intensity for $\mathrm{MN}$ is very small, that for BN has almost same intensity as that of $\mathrm{Si}-\mathrm{O}$, revealing that significant $\mathrm{Si}-\mathrm{N}$ bonds exist for BN sample. In addition, the XPS spectra of three samples in nitrogen binding energy region [Fig. 1(b)] show that while only one broad $\mathrm{N}-\mathrm{O}$ bonding peak is observed at $401-402 \mathrm{eV}^{11}$ for $\mathrm{TN}$ sample, additional peak due to $\mathrm{N}-\mathrm{Si}$ bond at $398.2 \mathrm{eV}$ (Ref. 12) is observed for BN. The existence of $\mathrm{Si}-\mathrm{N}$ bonds for $\mathrm{BN}$ indicates that nitrogen is incorporated into the bottom
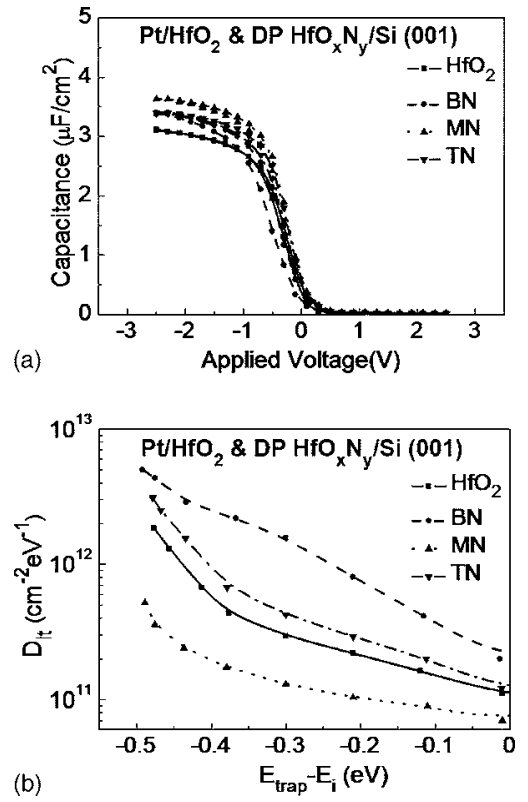

FIG. 2. (a) Capacitance-voltage curves and (b) the interface state densities of MOS capacitors with $\mathrm{HfO}_{2}$ and DP (depth profiled controlled) $\mathrm{HfO}_{x} \mathrm{~N}_{y}$ as a gate insulator.

layer of $\mathrm{HfO}_{2}$, forming an interface layer with $\mathrm{Si}-\mathrm{N}$ bonds as well as $\mathrm{Si}-\mathrm{O}$ bonds. However, no $\mathrm{Si}-\mathrm{N}$ bond is formed for $\mathrm{TN}$ since nitrogen incorporation occurs only at the top portion of the oxide, which is away from the interface region. The transmission electron microscopy analysis (data not shown) has shown that the total thickness of BN $(4.5 \mathrm{~nm})$ was slightly thicker than those of MN or TN (4.2 nm), due to the larger interlayer thickness. This is due to the generation of higher concentration $\mathrm{O}$ radicals by $\mathrm{N}$ addition ${ }^{13}$ resulting in the formation of oxynitride interlayer, which is consistent with XPS results. Similar results were observed for fully nitrided PE-ALD $\mathrm{TaO}_{x} \mathrm{~N}_{y}{ }^{6}$

To determine the nitrogen depth profiles more precisely, angle resolved XPS was carried out by measuring the XPS peak intensity additionally at $30^{\circ}$ detection angle. The integrated nitrogen peak intensity ratios between $30^{\circ}$ and $90^{\circ}$ detection angles $\left[I_{\mathrm{N}(30)} / I_{\mathrm{N}(90)}\right]$ of $\mathrm{BN}$ sample is smaller than 1 , indicating that the nitrided layer is located away from the surface. On the contrary, $I_{\mathrm{N}(30)} / I_{\mathrm{N}(30)}$ is larger than 1 for TN and $\mathrm{MN}$, indicating that the nitrided layers of these samples are located closer to the surface region than BN. Especially, $I_{\mathrm{N}(30)} / I_{\mathrm{N}(90)}$ of $\mathrm{TN}$ (1.55) is larger than that of $\mathrm{MN}(1.21)$, indicating that the nitrided layer of sample TN is located closer to the surface than MN. These angle resolved XPS results together with the deconvoluted XPS spectra strongly suggest that the depth profile controlled nitrogen incorporation was achieved as we intended.

Figure 2(a) shows the $C$ - $V$ measurement results of MOS capacitors with these three films as insulators. That of PEALD $\mathrm{HfO}_{2}$ is also shown as a reference. Compared to $\mathrm{HfO}_{2}$, the EOTs of all three samples have been reduced $(1.10 \mathrm{~nm}$ for $\mathrm{BN}, 1.07 \mathrm{~nm}$ for $\mathrm{TN}$, and $1.00 \mathrm{~nm}$ for $\mathrm{MN}$ ). The smaller EOT of $\mathrm{BN}$ than that of $\mathrm{HfO}_{2}$ is attributed to the larger dielectric constant of the interface layer. On the contrary, the smaller EOTs of TN and $\mathrm{MN}$ than that of $\mathrm{HfO}_{2}$ are due to the increase in dielectric constants of the films. In addition, the larger EOT of TN than that of MN seems to be related to the postdeposition annealing process performed in this experi- 


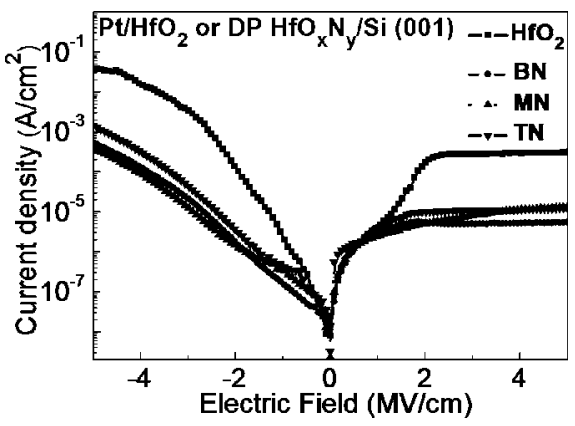

FIG. 3. Leakage current density-voltage curves of MOS capacitors with $\mathrm{HfO}_{2}$ and DP (depth profiled controlled) $\mathrm{HfO}_{x} \mathrm{~N}_{y}$ as a gate insulator.

ment. Without PDA, the EOTs of TN and MN were almost the same as $1.00 \mathrm{~nm}$. After PDA, however, the EOT of TN increased to $1.07 \mathrm{~nm}$, while that of $\mathrm{MN}$ remained constant. We speculate that the increase in EOT for TN is due to the partial removal of nitrogen from the topmost nitrided layer. This agrees with a previous report on annealing of nitrided film showing significant nitrogen removal near the top surface than bulk. ${ }^{14}$ However, for MN, having a nitrided layer in the middle of the film, the nitrogen atoms are not removed by PDA.

Figure 2(a) also shows that the $C-V$ curve of $\mathrm{BN}$ has the largest hysteresis of $0.12 \mathrm{~V}$ with $V_{\mathrm{FB}}=-0.14 \mathrm{~V}$. This is a similar result to fully nitrided $\mathrm{HfO}_{x} \mathrm{~N}_{y}$ mentioned above. The large hysteresis and flatband voltage shift are due to the incorporation of too much nitrogen into the interface layer region, as mentioned above. In contrast, the $V_{\mathrm{FB}}$ is not shifted and the hysteresis is relatively smaller $(<0.08 \mathrm{~V})$ for $\mathrm{MN}$ and TN samples. For these samples, since nitrogen is incorporated only in the middle or top position, the interfaces are not degraded.

To compare the quality of the interfaces quantitatively, the interface state densities $\left(D_{\mathrm{it}}\right)$ were obtained for these samples as a function of $E_{\text {trap }}-E_{i}$, where $E_{\text {trap }}$ and $E_{i}$ are the trap level in the band gap and the intrinsic Fermi level of $\mathrm{Si}$, respectively [Fig. 2(b)]. The $D_{\text {it }}$ of BN is the largest in the whole half range of band gap, almost twice or more than that of TN. This result agrees with previous reports showing that the interface quality for postdeposition nitridation is better than predeposition nitridation. ${ }^{3}$ However, the best interface quality was obtained for $\mathrm{MN}$ (near of midgap $D_{\mathrm{it}}=0.7$ $\times 10^{11} \mathrm{~cm}^{-2} \mathrm{eV}^{-1}$ ) among the three. Based on XPS results, while the interface of TN is totally lack of nitrogen, $\mathrm{MN}$ has small nitrogen atoms incorporated into the interface region. The incorporation of proper amount of nitrogen leads to reduction of the interface states by relaxing the interfacial strain or passivating defects. ${ }^{15}$ Thus, while the $D_{\text {it }}$ of $\mathrm{HfO}_{2}$ and TN are almost the same with each other $\left(1.2 \times 10^{11} \mathrm{~cm}^{-2} \mathrm{eV}^{-1}\right)$ at the near of midgap, the MN has lower $D_{\text {it }}$ value. The changes in $D_{\text {it }}$ at the whole half of the band gap show the same trend with midgap $D_{\mathrm{it}}$ value, $\mathrm{BN}>\mathrm{TN}>\mathrm{HfO}_{2}>\mathrm{MN}$.

All three samples have shown almost an order of magnitude lower leakage currents and higher dielectric breakdown voltages than PE-ALD $\mathrm{HfO}_{2}$. Figure 3 shows the current density-voltage measurement results for the same samples. The leakage current densities of gate injection at $-1 \mathrm{MV} / \mathrm{cm}$ of all three samples were almost an order of magnitude lower than that of PE-ALD $\mathrm{HfO}_{2}$. Among the three samples, the leakage current densiy of BN sample at
$-1 \mathrm{MV} / \mathrm{cm}$ was measured to be the lowest $\left(1 \times 10^{-7} \mathrm{~A} / \mathrm{cm}^{2}\right)$, which is almost same as fully nitrided $\mathrm{HfO}_{x} \mathrm{~N}_{y}$ film, probably due to the thick interfacial layer. Meanwhile, the leakage current densities of TN $\left(3.5 \times 10^{-7} \mathrm{~A} / \mathrm{cm}^{2}\right)$ and $\mathrm{MN}\left(2 \times 10^{-7} \mathrm{~A} / \mathrm{cm}^{2}\right)$ are slightly higher, but comparable to that of BN. These leakage current values are comparable to previously reported one on nitrided $\mathrm{HfO}_{2}$ prepared by other methods such as high temperature $\mathrm{NH}_{3}$ annealing. ${ }^{3}$

A more prominent benefit of nitrogen depth profile control is observed in the reliability. The 50\% failure electric field of MN sample is improved significantly (2 MV higher) and the standard deviation of failure voltages is about 2.5 times smaller than that of $\mathrm{HfO}_{2}$ (data not shown). Thus, the nitrogen depth profile control provides much more opportunity to tune the electrical properties of high $k$ gate oxide. By nitrogen depth profiling, the fabrication of high $k$ gate oxide with good properties in terms of EOT, $D_{\mathrm{it}}$, and high dielectric strength is achievable, which has not been possible by other nitridation methods. The current results manifest the benefits of ALD, enabling the control of the compositional depth profiling with atomic accuracy. A similar technique would be applicable to produce nanothin films for various applications. Especially, the excellent conformality of ALD together with controllability of depth profiling is expected to greatly contribute to the fabrication of next generation devices.

The authors gratefully thank Hyoungsub Kim in Sungkyunkwan University for helpful discussions in electrical measurements. This work was supported by the Korea Research Foundation (Basic Research Promotion Fund, KRF-2006-311-D00114 and MOEHRD, KRF-2005-005J13102) and POSTECH Core Research Program. One of the authors (W.J.M.) was financially supported by the second stage of the Brain Korea 21 project in 2007.

${ }^{1}$ D. A. Buchanan, IBM J. Res. Dev. 43, 245 (1999).

${ }^{2}$ E. P. Gusev, V. Narayanan, and M. M. Frank, IBM J. Res. Dev. 50, 387 (2006).

${ }^{3}$ H.-J. Cho, C. S. Kang, K. Onishi, S. Fopalan, R. Nieh, R. Choi, E. Dharmarajan, and J. C. Lee, Tech. Dig. - Int. Electron Devices Meet. 2001 655.

${ }^{4}$ K. Sekine, S. Inumiya, M. Sato, A. Kaneko, K. Eguchi, and Y. Tsunashima, Tech. Dig. - Int. Electron Devices Meet. 2003103.

${ }^{5}$ W. J. Maeng, S. J. Lim, Soon-Ju Kwon, and H. Kim, Appl. Phys. Lett. 90, 062909 (2007).

${ }^{6}$ W. J. Maeng, J. W. Lee, J. M. Myoung, and H. Kim, Jpn. J. Appl. Phys., Part 1 46, 3224 (2007).

${ }^{7}$ K. J. Yang and C. Hu, IEEE Trans. Electron Devices 46, 1500 (1999).

${ }^{8}$ Y. Lee, S. Kim, J. Koo, I. Kim, J. Choi, H. Jeon, and Y. Won, J. Electrochem. Soc. 153, G353 (2006).

${ }^{9}$ T. Ino, Y. Kamimuta, M. Suzuki, M. Koyama, and A. Nishiyama, Jpn. J. Appl. Phys., Part 1 45, 2908 (2006).

${ }^{10}$ Handbook of X-ray Photoelectron Spectroscopy, edited by J. Chastain (Perkin-Elmer, Eden Prairie, MN, 1992), Vol. 1, p. 57.

${ }^{11}$ L. Q. Zhu, L. D. Zhang, G. H. Li, G. He, M. Liu, and Q. Fang, Appl. Phys. Lett. 88, 232901 (2006).

${ }^{12}$ G. Pant, A. Gnade, M. J. Kim, R. M. Wallace, B. E. Gnade, M. A. Quevedo-Lopez, P. D. Kirsch, and S. Krishnan, Appl. Phys. Lett. 89, 032904 (2006).

${ }^{13}$ N. Haraki, S. Nakano, S. Ono, and S. Teii, Electr. Eng. Jpn. 149, 14 (2004).

${ }^{14}$ T. Nabatame, K. Iwamoto, H. Ota, K. Tominaga, H. Hisamatsu, T. Yasuda, K. Yamamoto, W. Mizubayashi, Y. Morita, M. Ohno, T. Horikawa, and A. Toriumi, Symp. on VLSI Tech. Dig. of Technical Papers 2003, 25.

${ }^{15}$ M. Cho, H. B. Park, J. Park, SW. Lee, C. S. Hwang, G. H. Jang, and J. Jang, Appi. Phys. Irett. 83, 5503 (2003): ermsconditions. Downloaded to IP 